\title{
Spatiotemporal Variation Characteristics of Ecosystems and their Driving Forces in the Min Delta Urban Agglomeration
}

\author{
Ruitong Cheng ${ }^{1}$, Wenhui Chen ${ }^{1 *}$, Sijia Wu ${ }^{1}$ and Jinhuang $\operatorname{Lin}^{1}$ \\ 1 College of Geography, Fujian Normal University \\ *Corresponding Author, Email: whchenfz@sohu.com
}

Received: 20 July 2018; Accepted: 16 Nov 2018

Key words: Min Delta urban agglomeration, ecosystem type transfer, Comprehensive Dynamic Index of Ecosystems, driving force

\begin{abstract}
This paper uses four years of ecosystem classification data, from 2000, 2005, 2010 and 2015, to analyse the spatiotemporal variation characteristics of the ecosystems of counties and cities in the Min Delta urban agglomeration over 15 years across four aspects, including changes in the ecosystem area for each period, a transfer matrix of the counties and cities, the comprehensive dynamic ecosystem index, and the forces driving these changes. The results show that: (1) from 2000 to 2015, the total area of farmland, forest and shrub ecosystems in the Min Delta urban agglomeration decreased, while the total area of urban, wetland and grassland ecosystems has increased. There are spatiotemporal differences and patterns in the area change and transfer of various ecosystems. The series of scales and proportion of ecosystem types in the counties and cities of the Min Triangle show that there is a two-way transfer between farmland and urban ecosystems. In addition, there are spatiotemporal differences in the transfer of these two ecosystems. Forest ecosystems are transferred into farmland, urban and grassland ecosystems at different levels. In the eastern part of the Min Triangle, wetlands are mostly transferred to urban ecosystems, and the western regions are mostly transferred to forests and farmland. (2) For the comprehensive dynamic index of the Min Delta urban agglomeration, from 2000 to 2015, the degree of ecosystem dynamics was higher in each period than the previous, and the dynamics in the eastern and central parts were higher than those in the west and south for the same period. From 2000 to 2005, the comprehensive dynamic index was below $0.2 \%$. The dynamic index of Longhai in Xiamen and Zhangzhou increased significantly from 2005 to 2010 from that of the previous period, and their values all exceeded $0.9 \%$. From 2010 to 2015, the area with a large change in the dynamic index expanded to the east and south from the central area of Xiamen. The dynamics in the northwest did not sufficiently increase. (3) The GDP, value of agricultural production, forestry, and fisheries, secondary and tertiary industries, urbanization rate, and permanent residents are important factors influencing ecosystems. The driving effects of these socioeconomic indicators and urban population development have different degrees of significance on farmland, urban, forest and wetland ecosystems during different periods of the Delta's urban agglomeration.
\end{abstract}




\section{INTRODUCTION}

The pattern and spatial structure of ecosystems reflect their spatial distribution laws and the relationship between their spatial structures, and determine the overall status and spatial differences of ecosystem services, which provide an important basis for the conservation and utilization of ecosystem services according to regional characteristics (Xu et al., 2008). Land use/cover change (LUCC) causes changes in surface structure and affects surface material circulation and energy flow, which affects the structure and function of the entire ecosystem and thereby affects ecosystem services and our quality of life (Shi, Cui, \& Yin, 2010).

Research on land use and cover began in the 1990s and divided the LUCC research field into three factions, i.e., the North American, European, and Japanese factions ( $\mathrm{Yu}, \mathrm{H}$. R. \& Pu, 2012). From a macro perspective, North American research focuses on studying LUCC conditions on a large scale and their relationship with global change. European research focuses more on the response of land-use changes to its associated land resources and food supply, and attempts to predict future changes in natural resources and the environment by building models, while Japanese research is largely based on using advanced computer technology to quantitatively study regional land use and cover changes through quantitative and economic models, and attempting to predict future conditions ( $\underline{\text { Song, 2016). }}$ )

In recent years, in the context of the rapid development of GIS and RS technology, scholars have used GIS and RS technology to spatially analyse ecosystem patterns based on land use and land cover research. Du et al. (2015) used RS and GIS to analyse the dynamic changes of the main ecological elements in the Tarim River Basin over the past 20 years, and to evaluate their ecological environment. Wang et al. (2014) used RS and GIS to analyse the dynamic changes of the spatial pattern of ecosystems in Jiangxi Province in China from the aspects of landscape pattern and the variation tendency and rate of change in spatial structures. Yu, G. M. (2011) conducted a spatiotemporal analysis of the Xilin Gol League ecosystem from the perspective of ecosystem types and their transformation and

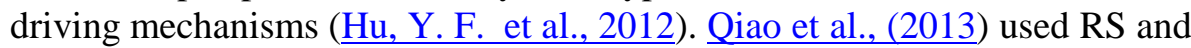
GIS techniques to analyse the spatiotemporal patterns of the Qinghai-Tibet Plateau ecosystem from the perspective of an ecosystem transfer matrix and dynamics, and qualitatively analysed the driving forces of ecosystem change (Mou, Zhao, \& Rao, 2016). Scholars' research on the spatial analysis of the spatial and temporal patterns of ecosystems is concentrated in areas where humanities and natural drivers are active or in ecologically vulnerable areas, many studies on ecosystems have focused on a small area, or have covered large areas and have not considered the differences between cities (Zhang, Zhang, \& Zhang, 2017). Therefore, their conclusions may be too general.

The Min Delta, also referred to as the Gold Dust River, is an open coastal area in China similar to the renowned economic zones of the Yangtze and Pearl River Delta urban agglomerations. Development in the Min Delta has clear geographical advantages; however, it is not as rapid as the development of the Yangtze and Pearl River Delta urban agglomerations. In recent years, many scholars have studied the politics, economy (Meng, Li, \& Lu, 2014), culture (Lu, L. \& Tang, 2014; Zhou \& Jiang, 2015), environment (Liu, Zhang, \& Zhang, 2014; Liao et al., 2015) and technology (Zhu \& Li, 2015; Chen et al., 2013) of the Yangtze and Pearl River Delta urban agglomeration regions. However, there are few studies on the Min Delta, and most of them have been limited to the economy (Yan, 
2007), transportation and tourism ( $\mathrm{Lu}, \mathrm{Y}$. H. \& Nie, 2008), and seldom consider the ecosystem. A small number of scholar have studied the landscape patterns and land use Xiamen, Zhangzhou and Quanzhou (Lin et al., 2018; Hu, S. S., Chen, \& Chen, 2018; Li, Z. Y. \& Chen, 2018), which are cities located in the Min Delta, but they are rarely specific to the counties and urban areas of the Delta.

The Chinese government advocates sustainable development, therefore, the population must consider sustainable resource use during development. However, with economic and technological development, infrastructure can easily be developed in the natural ecosystem, which can intervene in the ecosystem's functioning and cause a series of ecological problems $(\mathrm{Li}, \mathrm{H}$., Zhao, \& Wang, 2015; Fan \& Jiang, 2015). Many areas have failed to fully utilize the advantages of the regional ecosystem, as they have over-exploited resources or transformed ecosystem functions. This contradicts the requirements of sustainable development and prevents the regional economy from achieving a breakthrough.

Studying spatial changes in ecosystems is vital for the sustainable development of regional economies while providing a foundation for further research on the ecological security of Gulf-type urban agglomeration.

\section{STUDY AREA AND METHODOLOGY}

\subsection{Study area introduction}

The Min Delta is an open, coastal area of China located between $116^{\circ} 53^{\prime} 21^{\prime \prime}$ - $119^{\circ} 01^{\prime} 38^{\prime \prime} \mathrm{E}$ and $23^{\circ} 33^{\prime} 20^{\prime \prime}-25^{\circ} 56^{\prime} 45^{\prime} \mathrm{N}$ (Fiqure 1). It contains three cities in Fujian Province, Xiamen, Zhangzhou and Quanzhou, and a total of 28 cities and counties under its jurisdiction. The Min Delta covers an area of 25,314.39 $\mathrm{km}^{2}$ and has a population exceeding 17 million people.

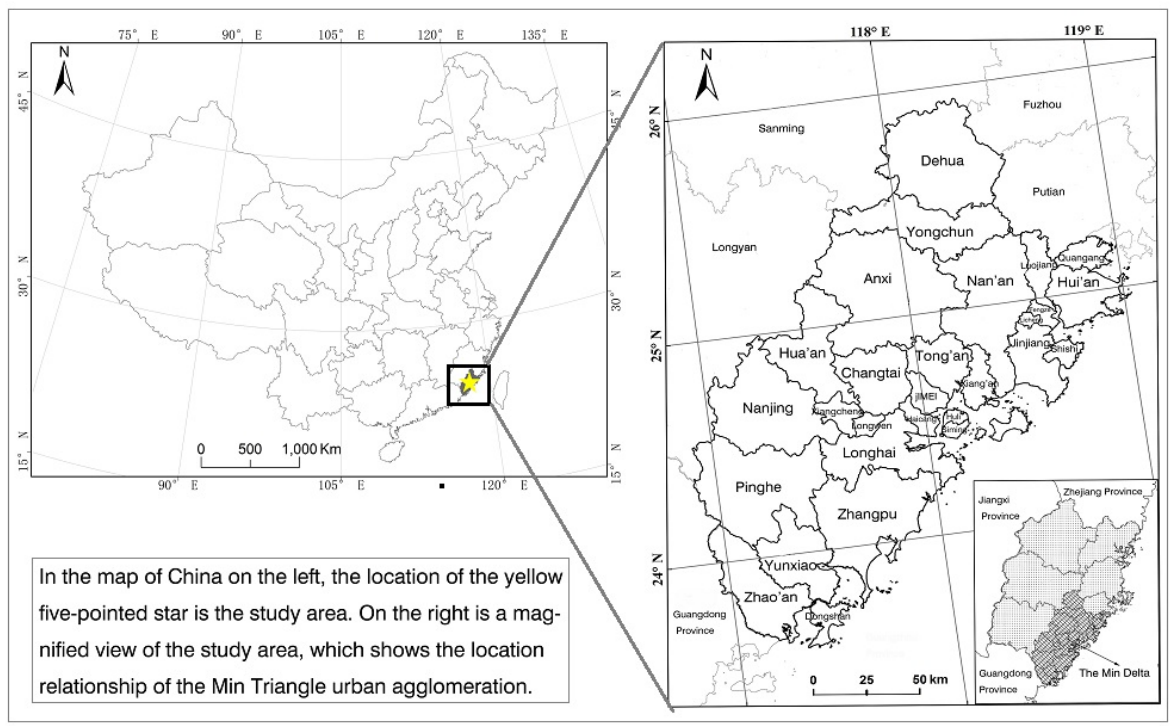

Figure 1. Location of the study area

Min Delta is situated on the southeast coast of China, with a subtropical marine monsoon climate - the summer is hot and rainy while the winter is 
mild and rainless - and the vegetation is mainly evergreen broad-leaved forest. The region has advantageous conditions for socioeconomic development, with plains, natural harbors, national-level export-oriented agricultural demonstration zones, and industrial cluster gathering. It has eight characteristic industrial chains and seven industrial clusters with an output value exceeding RMB 100 billion. Although the economic strength and the gap between the Yangtze and Pearl River Delta urban agglomerations are relatively large, the regional advantages are clear and economic development is stable and rapid.

\subsection{Methodology}

\subsubsection{Data and pre-processing}

The data used in this study include: (1) three series of satellite data taken by Landsat TM (for 2005 and 2010), ETM+ (for 2000), and OLI (for 2015), which are freely available from the Geospatial Data Cloud (2010). These images were preprocessed by remote-sensing calibration, atmospheric correction by FLAASH, geometric precision correction, image fusion by Gram-Schmidt, and image cropping. Combined with the Fujian Vegetation Type and Land-use maps, a SHP file for land use in the Min Delta can be obtained by visual image interpretation (Environmental Protection Department of China \& Chinese Academy of Science, 2017). The result was compared to the actual ecosystem type in the field and from images obtained from Google Earth, and the accuracy reached 88\%. The ecosystem type was then classified by land use data. Based on this data and the Min Delta classification system, the visual interpretation results were divided into seven ecosystems using ArcGIS, and a spatial distribution vector map of the four ecosystem types was obtained. (2) statistical data was collected regarding the cities and countries of Min Delta from 2000 to 2015, obtained from the Statistical Yearbooks of Fujian, Fujian Rural Areas, Xiamen, Zhangzhou, and Quanzhou, and China Social Economic Statistical Yearbooks. Indices such as GDP, secondary and tertiary industry, urbanization rate, agricultural output value, and forestry and fishery production values were obtained, and data were processed by min-max normalization.

\subsubsection{Methodology introduction}

Based on the vector data of ecosystem types in 2000, 2005, 2010 and 2015, this study used the counties as statistical units for analyzing the changes in each ecosystem area in the delta urban agglomeration over the 15 -year period. The transfer matrix of each ecosystem was calculated every five years. The colour of each grade was used to represent the transfer ratio of each ecosystem in each county during the study period, and the area of the matrix was used to represent the scale of urban ecosystem transfer in the county. The scale of ecosystem transfer was expressed on a map of regional administrative divisions to analyse the dynamic spatiotemporal characteristics of ecosystems in the Min Delta urban agglomeration. The dynamics of the integrated ecosystems in the Min Delta urban agglomeration were calculated for each period, the extent and trend of changes in the types of ecosystems in Min Delta urban agglomeration during the 15-year period were analysed, and areas of intense ecosystem change were identified. Correlation analysis was combined with the dynamic degree 
of a single ecosystem to analyse the relationship between the dynamic degree and driving force index during the study period, and to explain the main factors driving the ecological changes in the Min Delta urban agglomeration.

\subsubsection{Types of ecosystem}

The ecosystem types in the Min Delta were mainly determined using the National Technical Guide for Remote Sensing Survey and Assessment Project of Ten Year Changes in Ecological Environment (2000-2010) (Environmental Protection Department of China \& Chinese Academy of Science, 2017), and the urban agglomeration was divided into seven major ecosystem types: farmland, grassland, wetland, town, forest, shrub and others ( $\underline{\text { Table } 1}$ ).

Table 1. Ecosystem classification in the Min Delta

\begin{tabular}{|c|c|c|}
\hline First class & Secondary class & Standards \\
\hline \multirow[t]{4}{*}{$\begin{array}{l}\text { Forest } \\
\text { Ecosystem }\end{array}$} & $\begin{array}{l}\text { Broad- } \\
\text { leaved forest }\end{array}$ & $\begin{array}{l}\text { Natural or semi-natural vegetation, } \mathrm{H}=3-30 \mathrm{~m}, \mathrm{C}>20 \% \text {, } \\
\text { broadleaf. }\end{array}$ \\
\hline & Coniferous forest & $\begin{array}{l}\text { Natural or semi-natural vegetation, } \mathrm{H}=3-30 \mathrm{~m}, \mathrm{C}>20 \% \text {, } \\
\text { coniferous. }\end{array}$ \\
\hline & $\begin{array}{l}\text { Coniferous mixed } \\
\text { forest }\end{array}$ & $\begin{array}{l}\text { Natural or semi-natural vegetation, } \mathrm{H}=3-30 \mathrm{~m} \text {, } \\
\mathrm{C}>20 \%, 25 \%<\mathrm{F}<75 \% \text {. }\end{array}$ \\
\hline & Sparse forest & $\begin{array}{l}\text { Natural or semi-natural vegetation, } \mathrm{H}=3-30 \mathrm{~m}, \mathrm{C}=4- \\
20 \% \text {. }\end{array}$ \\
\hline \multirow[t]{3}{*}{$\begin{array}{l}\text { Shrub } \\
\text { Ecosystem }\end{array}$} & $\begin{array}{l}\text { Broad-leaved } \\
\text { shrub }\end{array}$ & $\begin{array}{l}\text { Natural or semi-natural vegetation, } \mathrm{H}=0.3-5 \mathrm{~m} \text {, } \\
\mathrm{C}>20 \% \text {, broadleaf. }\end{array}$ \\
\hline & Coniferous shrub & $\begin{array}{l}\text { Natural or semi-natural vegetation, } \mathrm{H}=0.3-5 \mathrm{~m} \text {, } \\
\mathrm{C}>20 \% \text {, coniferous. }\end{array}$ \\
\hline & Sparse shrub & $\begin{array}{l}\text { Natural or semi-natural vegetation, } \mathrm{H}=0.3-5 \mathrm{~m}, \mathrm{C}=4- \\
20 \% \text {. }\end{array}$ \\
\hline \multirow[t]{4}{*}{$\begin{array}{l}\text { Grassland } \\
\text { Ecosystem }\end{array}$} & Meadow & $\begin{array}{l}\text { Natural or semi-natural vegetation, } \quad K>1.5 \text {, } \\
\text { soils that are water-saturated, } H=0.03-3 m, C>20 \% \text {. }\end{array}$ \\
\hline & Grassland & $\begin{array}{l}\text { Natural or semi-natural vegetation, } K=0.9-1.5 \text {, } \\
\mathrm{H}=0.03-3 \mathrm{~m}, \mathrm{C}>20 \% \text {. }\end{array}$ \\
\hline & Grass & $\begin{array}{l}\text { Natural or semi-natural vegetation, } \mathrm{K}>1.5, \mathrm{H}=0.03- \\
3 \mathrm{~m}, \mathrm{C}>20 \% \text {. }\end{array}$ \\
\hline & Sparse grassland & $\begin{array}{l}\text { Natural or semi-natural vegetation, } \mathrm{H}=0.03-3 \mathrm{~m}, \mathrm{C}=4- \\
20 \% \text {. }\end{array}$ \\
\hline \multirow[t]{2}{*}{$\begin{array}{l}\text { Farmland } \\
\text { Ecosystem }\end{array}$} & Cultivated field & $\begin{array}{l}\text { Artificial vegetation, land disturbances, soundings or } \\
\text { drought crops }\end{array}$ \\
\hline & Garden & Artificial vegetation, $\mathrm{H}=0.3-30 \mathrm{~m}, \quad \mathrm{C}>20 \%$ \\
\hline \multirow[t]{3}{*}{$\begin{array}{l}\text { Wetland } \\
\text { Ecosystem }\end{array}$} & Swamp & $\begin{array}{l}\text { Natural or semi-natural vegetation, } \mathrm{T}>2 \text { or wet soil, } \\
\mathrm{H}=0.3-30 \mathrm{~m}, \mathrm{C}>20 \% \text {. }\end{array}$ \\
\hline & Lake & Natural or artificial water surface, stillness. \\
\hline & River & Natural or artificial water surface, flowing. \\
\hline Urban & Residential & Artificial hard surface, residential building. \\
\hline \multirow[t]{2}{*}{ Ecosystem } & $\begin{array}{l}\text { Urban Green } \\
\text { Space }\end{array}$ & $\begin{array}{l}\text { Artificial vegetation, distributed around the artificial } \\
\text { surface, } H=0.03-30 \mathrm{~m}, \mathrm{C}>20 \% \text {. }\end{array}$ \\
\hline & $\begin{array}{l}\text { Industrial and } \\
\text { mining use }\end{array}$ & $\begin{array}{l}\text { Artificial hard surface, production building or static } \\
\text { features or manual surface excavation. }\end{array}$ \\
\hline \multirow[t]{2}{*}{$\begin{array}{l}\text { Other } \\
\text { Ecosystem }\end{array}$} & Desert & $\begin{array}{l}\text { Naturally loose surface, sandy or loamy or high salt or } \\
\text { microbial cover }\end{array}$ \\
\hline & Bare land & Naturally loose surface, sandy or loamy, hard surface. \\
\hline
\end{tabular}




\subsubsection{Transfer matrix and transfer matrix ratio}

The type of ecosystem transfer matrix reflects the dynamic relationship between the 'Initial' ecosystem and the 'Terminal Stage' in the study area (Yu, G. M., 2011). The transfer matrix can intuitively determine the direction and area variation of ecosystem type with the following formula:

$$
S_{i j}=\left|\begin{array}{cccc}
S_{11} & S_{12} & \cdots & S_{1 n} \\
S_{21} & S_{22} & \cdots & S_{2 n} \\
\cdots & \ldots & \cdots & \cdots \\
S_{n 1} & S_{n 2} & \cdots & S_{n n}
\end{array}\right|
$$

where $n=7$ represents the various ecosystems, $i$ and $j$ represent the preand post-transfer ecosystem type, respectively, and $S_{i j}$ represents the area that ecosystem $i$ has transferred to ecosystem $j$.

The rate of the transfer matrix is another transfer matrix in itself, as it is the result of normalizing the transfer area and can intuitively compare the changes between each ecosystem using the following formula:

$$
P_{i j}=\left|\begin{array}{cccc}
P_{11} & P_{12} & \cdots & P_{1 n} \\
P_{21} & P_{22} & \cdots & P_{2 n} \\
\cdots & \cdots & \cdots & \cdots \\
P_{n 1} & P_{n 2} & \cdots & P_{n n}
\end{array}\right| \quad P_{i j}=S_{i j} / \sum_{j=1}^{n} S_{i j}
$$

where $P_{i j}$ represents the ratio of the area of ecosystem $i$ transfer to ecosystem $j$.

\subsubsection{Comprehensive dynamic ecosystem index}

The comprehensive dynamic ecosystem index can reflect the speed of ecosystem change (Qiao et al., 2013) with the following formula:

$$
E=\frac{\sum_{i=1}^{n} \Delta E_{i-j}}{2 \sum_{i=1}^{n} \Delta E_{i}} \times \frac{1}{T} \times 100 \%
$$

where $E i$ is the area of the initial ecosystem, $\triangle E i-j$ is the absolute value of the area transferred from ecosystem $i$ to another ecosystem, and $T$ is the time taken for the change to occur.

\subsubsection{Dynamic index of a single ecosystem}

The dynamic index of a single ecosystem expresses the quantitative changes of a certain ecosystem type over a certain period (Mou, Zhao, \& Rao, 2016) with the following formula:

$$
E_{\mathrm{d}}=\frac{E U_{b}-E U_{a}}{E U_{a}} \times \frac{1}{T} \times 100 \%
$$

where $E_{\mathrm{d}}$ is the dynamic index of a single ecosystem, and $E U_{a}$, and $E U_{b}$ represent the area of an ecosystem type at the beginning and end of the study period respectively.

\subsubsection{Co-linear test}

Co-linearity means that there is a strong linear correlation between variables. In this study, when exploring the correlation between the dynamics of a single ecosystem and various socio-economic indicators, the 
co-linearity is first selected to prevent co-linearity amongst the socioeconomic indicators, which results in the selection of indicators that are not representative. This paper uses a variance inflation factor (VIF) to test the co-linearity between variables, which uses the following formula:

$$
V I F_{\mathrm{i}}=\frac{1}{1-R_{\mathrm{i}}^{2}}
$$

where $R_{i}{ }^{2}$ represents the $\mathrm{R}^{2}$ value of the linear regression model of the remaining variables with the model variable $X_{i}$. If $\mathrm{VIF}>10$, there is strong co-linearity between these indicators.

\subsubsection{Pearson Correlation Coefficient}

The Pearson Correlation Coefficient is used to measure whether two data sets are above a line. It is used to measure the linear relationship between distance variables, using the following formula:

$$
\mathrm{r}=\frac{N \Sigma \mathrm{x}_{i} y_{i}-\Sigma x_{i} \Sigma_{y_{i}}}{\sqrt{N \Sigma x_{i}^{2}-\left(\Sigma x_{i}\right)^{2}} \sqrt{N \Sigma y_{i}^{2}-\left(\Sigma y_{i}\right)^{2}}}
$$

where $x_{i}$ and $y_{i}$ are two normal continuous variables, $N$ is the number of the variables, and $r$ is Pearson Correlation Coefficient. When $0.8 \leq|r| \leq 1$, there is a strong correlation between two variables; when $0.6 \leq|\mathrm{r}| \leq 0.8$, the two variables are very strongly correlated; when $0.4 \leq|\mathrm{r}| \leq 6$, they are moderately related; when $0.2 \leq|\mathrm{r}| \leq 0.4$, they are weakly correlated; and when $|\mathrm{r}| \leq 0.2$, they are very weakly correlated or uncorrelated.

\section{RESULTS AND ANALYSIS}

\subsection{The ecosystem area change of Min Triangle}

The whole area and the proportion of each ecosystem in the Min Delta urban agglomeration for 2000, 2005, 2010 and 2015 was calculated, and the results are presented in the ecosystem area change table for the Min Delta urban agglomeration (Table 2). Using counties as the unit, the area of each ecosystem in these four years is determined. The results show the ecosystem area change of counties and cities in the Min Delta urban agglomeration (Figure 2).

\begin{tabular}{|c|c|c|c|c|c|c|c|c|}
\hline \multirow{2}{*}{$\begin{array}{l}\text { The Type } \\
\text { of } \\
\text { Ecosystem }\end{array}$} & \multicolumn{2}{|c|}{ Year of 2000} & \multicolumn{2}{|c|}{ Year of 2005} & \multicolumn{2}{|c|}{ Year of 2010} & \multicolumn{2}{|c|}{ Year of 2015} \\
\hline & $\begin{array}{l}\text { Area } \\
\left(\mathrm{km}^{2}\right)\end{array}$ & $\begin{array}{l}\text { Proportion } \\
\text { (\%) }\end{array}$ & $\begin{array}{l}\text { Area } \\
\left(\mathrm{km}^{2}\right)\end{array}$ & $\begin{array}{l}\text { Proportion } \\
\text { (\%) }\end{array}$ & $\begin{array}{l}\text { Area } \\
\left(\mathrm{km}^{2}\right)\end{array}$ & $\begin{array}{l}\text { Proportion } \\
\text { (\%) }\end{array}$ & $\begin{array}{l}\text { Area } \\
\left(\mathrm{km}^{2}\right)\end{array}$ & $\begin{array}{l}\text { Proportion } \\
\text { (\%) }\end{array}$ \\
\hline Urban & 2234.48 & 8.86 & 2253.42 & 8.93 & 2634.65 & 10.45 & 3068.16 & 12.11 \\
\hline Wetland & 692.15 & 2.74 & 685.50 & 2.72 & 693.96 & 2.75 & 719.40 & 2.84 \\
\hline Forest & 15729.40 & 62.36 & 15696.71 & 62.24 & 15454.46 & 61.27 & 15375.44 & 460.66 \\
\hline Grassland & 132.43 & 0.53 & 136.30 & 0.54 & 163.02 & 0.65 & 142.76 & 0.56 \\
\hline Shrub & 999.12 & 3.96 & 992.48 & 3.94 & 1020.72 & 4.05 & 959.96 & 3.79 \\
\hline Farmland & 5323.54 & 21.11 & 5320.13 & 21.09 & 5153.04 & 20.43 & 4990.16 & 19.69 \\
\hline $\begin{array}{l}\text { Other } \\
\text { Ecosystems }\end{array}$ & 111.24 & 0.44 & 136.96 & 0.54 & 101.66 & 0.40 & 90.13 & 0.36 \\
\hline
\end{tabular}

Table 2. Ecosystem area change table in Min Triangle

As shown in Table 2 and Figure 2, from 2000 to 2015, the forest is the largest ecosystem. The area of other types of ecosystems decreases in the 
following order: farmland $>$ urban $>$ shrub $>$ wetland $>$ grassland $>$ other ecosystems. During these 15 years, the overall area of forest, farmland and shrubland ecosystems reduced, while the urban, wetland and grassland ecosystems expanded. (1) The proportion of forest ecosystem decreased from $62.36 \%$ in 2000 to $60.66 \%$ in 2015 , with a total reduction of 343.96 $\mathrm{km}^{2}$. The regions with the greatest decrease in area are concentrated in Pinghe, Zhangpu, Nan'an and Anxi. (2) The proportion of farmland decreased from $21.11 \%$ in 2000 to $19.69 \%$ in 2015 , with a reduction of $333.38 \mathrm{~km}^{2}$. The regions with the greatest decrease in area are concentrated in Zhangpu and Nan'an, while the area of farmland in Zhao'an slightly increased. (3) The proportion of shrub ecosystem decreased from $3.96 \%$ in 2000 to $3.79 \%$ in 2015 , with a reduction of $39.16 \mathrm{~km}^{2}$. (4) The proportion of urban ecosystem increased from $8.86 \%$ in 2000 to $12.11 \%$ in 2015 , with an increase in the area of $833.68 \mathrm{~km}^{2}$. The regions with the greatest increase are concentrated in Zhangpu, Nan'an, Longhai, Hui' an and Nanjing. (5) The proportion of wetland ecosystem increased from $2.74 \%$ in 2000 to $2.84 \%$ in 2015 , with a total increase in the area of $27.25 \mathrm{~km}^{2}$. The regions with the greatest increase from 2010 to 2015 are concentrated in Dongshan, Longhai and Hui'an, while the wetland areas in Tong'an reduced significantly, and the area of Jimei decreased significantly from 2010 to 2015. (6) The proportion of grassland increased from $0.53 \%$ in 2000 to $20.65 \%$ in 2015, with an increase in the area of $10.33 \mathrm{~km}^{2}$.
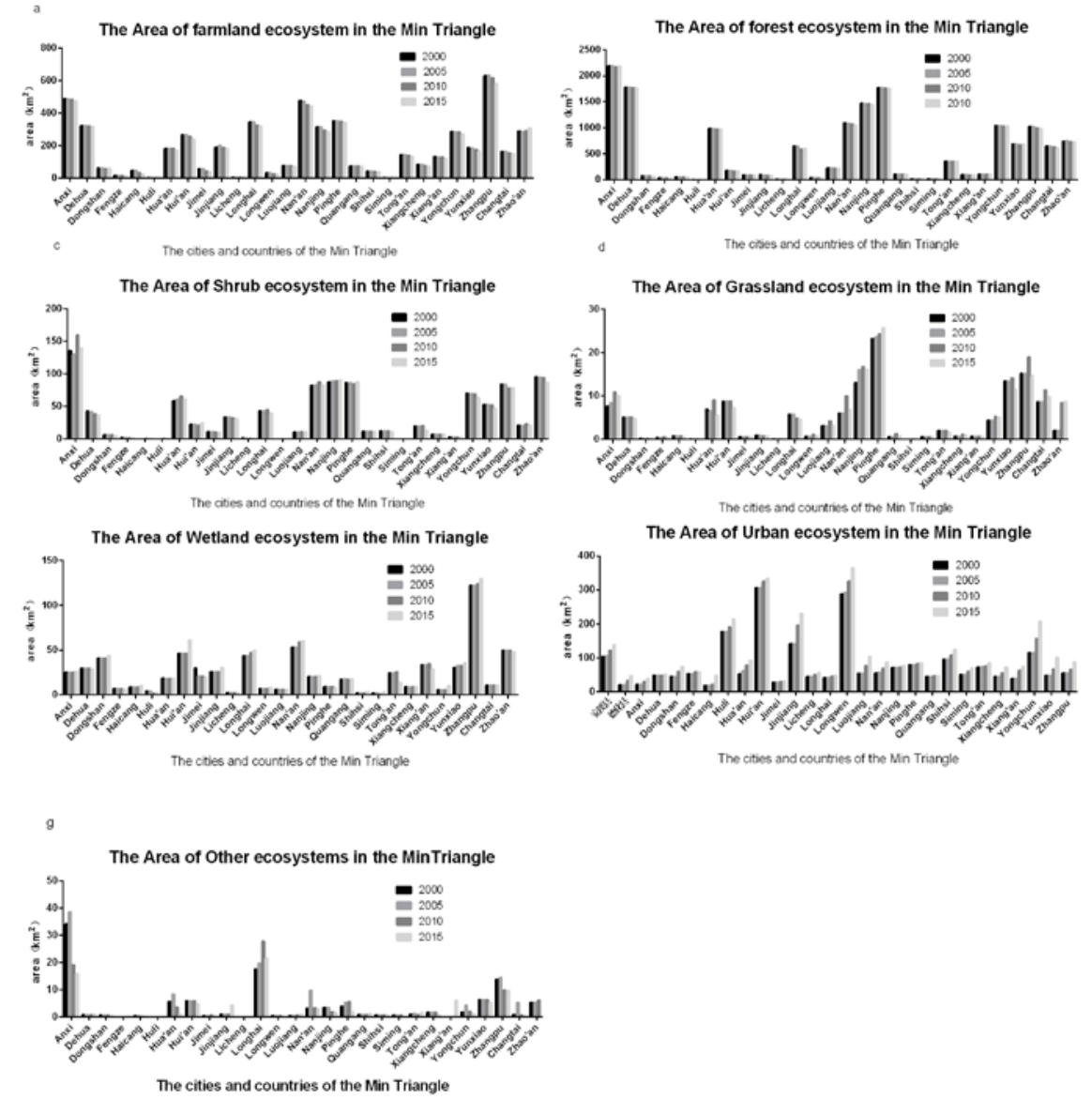

Figure 2. Area of ecosystem types in the Min Delta urban agglomeration 


\subsection{Transfer ratio matrices for the Min Triangle}

The transfer matrix was obtained by the Interest method in ArcGIS. The transfer ratio matrix was calculated from the transfer matrix. Time was used as a unit to divide the proportion of the transfer area for each ecosystem type into five levels according to the quantile classification method ( $\underline{\text { Table 3 }})$, and each level was represented by five colors (green, yellow, orange, red and blue). Several boxes were generated in a $7 \times 7$ grid. Similarly, the total area of ecosystem transfer in each county can also be divided into six levels (Table 4) by the quantile classification method for every five-year period, and the boxes' areas were displayed on a map.

Table 3. Classification of the value of transfer ratio

\begin{tabular}{lccccc}
\hline $\begin{array}{l}\text { Time } \\
\text { (year })\end{array}$ & $\begin{array}{c}1^{\text {st }} \text { Class } \\
(\%)\end{array}$ & $\begin{array}{c}2^{\text {nd }} \text { Class } \\
(\%)\end{array}$ & $\begin{array}{c}3^{\text {rd }} \text { class } \\
(\%)\end{array}$ & $\begin{array}{c}4^{\text {th }} \text { class } \\
(\%)\end{array}$ & $\begin{array}{c}5^{\text {th }} \text { class } \\
(\%)\end{array}$ \\
\hline $00-15$ & $\leq 0.001$ & $0.001-0.004$ & $0.004-0.018$ & $0.018-20.0$ & $\geq 20.00$ \\
\hline $05-10$ & $\leq 0.001$ & $0.003-0.017$ & $0.017-1.089$ & $1.089-20.0$ & $\geq 20.00$ \\
\hline $10-15$ & $\leq 0.020$ & $0.001-2.300$ & $2.300-21.30$ & $21.30-200.0$ & $\geq 200.00$ \\
\hline
\end{tabular}

Table 4. Classification of the value of transfer scale

\begin{tabular}{lllllll}
\hline & $\begin{array}{l}1^{\text {st }} \text { Class } \\
\left(\mathrm{Km}^{2}\right)\end{array}$ & $\begin{array}{l}2^{\text {nd }} \text { Class } \\
\left(\mathrm{Km}^{2}\right)\end{array}$ & $\begin{array}{l}3^{\text {rd }} \text { class } \\
\left(\mathrm{Km}^{2}\right)\end{array}$ & $\begin{array}{l}4^{\text {th }} \text { class } \\
\left(\mathrm{Km}^{2}\right)\end{array}$ & $\begin{array}{l}5^{\text {th }} \text { class } \\
\left(\mathrm{Km}^{2}\right)\end{array}$ & $\begin{array}{l}6^{\text {th }} \text { class } \\
\left(\mathrm{Km}^{2}\right)\end{array}$ \\
\hline $00-15$ & $\leq 0.1$ & $0.1-0.5$ & $0.5-3.0$ & $3.0-5.0$ & $5.0-9.0$ & $\geq 9.0$ \\
\hline $05-10$ & $\leq 10.0$ & $10.0-20.0$ & $20.0-30.0$ & $30.0-50.0$ & $50.0-70.0$ & $\geq 70.0$ \\
\hline $10-15$ & $\leq 10.0$ & $10.0-30.0$ & $30.0-50.0$ & $50.0-80.0$ & $80.0-120.0$ & $\geq 120.0$ \\
\hline
\end{tabular}

\subsubsection{Transfer ratio and scale of ecosystems in 2000-2005}

From the transfer ratio and scale of ecosystems in the cities and counties of the Min Triangle (Figure 3) from 2000 to 2005.

(1) In the northeastern region, a larger proportion of farmland transformed into urban ecosystems, while a large proportion of farmland in Xiamen, Jinjiang and Yunxiao was transformed into wetlands. Larger areas of farmland were converted into urban ecosystems in the southwestern and southeastern regions, and this was lower in the west than the east. A large proportion of farmland in Yongchun, Dehua, Zhao'an and Zhangpu were transformed into forest.

(2) In the west, a large proportion of grassland was converted into farmland and forest, while a small area was converted into wetland and urban ecosystems. In the northeast, a large proportion of grassland became urban, while a small area of grassland was transformed into forested land.

(3) In the east, a large proportion of wetland transformed into urban ecosystems, while in the west, a large proportion of wetland became farmland and forest.

(4) Meanwhile, urban ecosystems typically became farmland. 


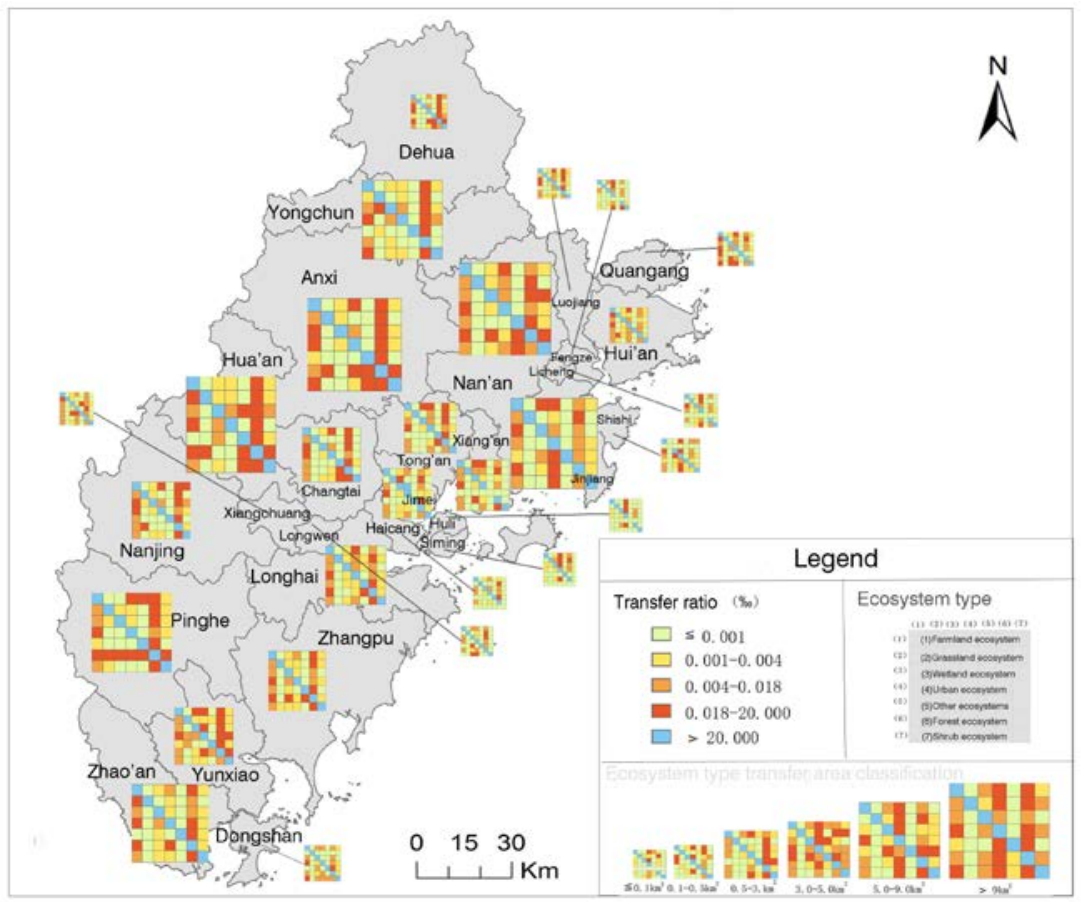

Figure 3. Transfer ratio and scale of ecosystems in the cities and countries of the Min Triangle (2000-2005)

\subsubsection{Transfer ratio and scale of ecosystems from 2005 to 2010}

The transfer ratio and scale of ecosystems in the cities and counties of the Min Triangle (Figure 4) from 2005 to 2010 were determined.

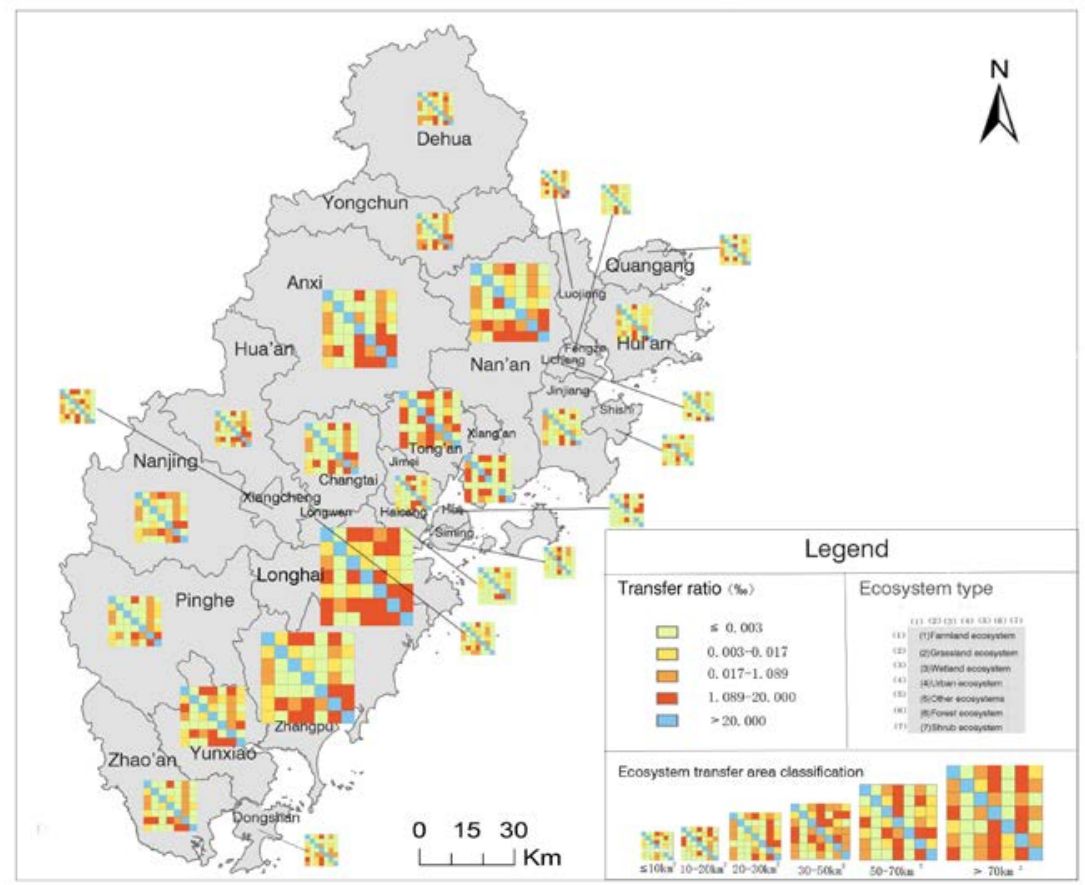

Figure 4. Transfer ratio and scale of ecosystems in the cities and countries of the Min Delta (2005-2010) 
(1) Throughout the Min Triangle, most of the transferred farmland ecosystems became urban. A large proportion of farmland in the southerncentral areas, such as Tong'an, Xiang'an, Jimei, Zhangpu, Longhai and Yunxiao, became urban, wetland and forest ecosystems.

(2) Most of the transferred grassland became forest, followed by farmland and small areas of urban ecosystems in Xiamen.

(3) In the west, south and northeast, a small area of urban ecosystems became farmland and forests, such as Luojiang, Quangang, Hui'an, Licheng and Shishi. The urban ecosystems of Tong'an, Xiang'an and Longhai became farmland, wetland and forest ecosystems.

(4) In the east of Xiamen, a large area of wetland ecosystems became urban, while in the western Min Triangle, a large area of wetland became farmland and forest ecosystems.

(5) Forest ecosystems mostly transformed into urban and grassland regions. In Tong'an, Xiang’an, Longhai, Zhao'an and Dongshan, a large area of forest became farmland.

\subsubsection{Transfer ratio and scale of ecosystems from 2010 to 2015}

According to the transfer ratio and scale of ecosystems in the cities and counties of the Min Triangle (Figure 5) from 2010 to 2015, the change is more notable than that in the other periods.

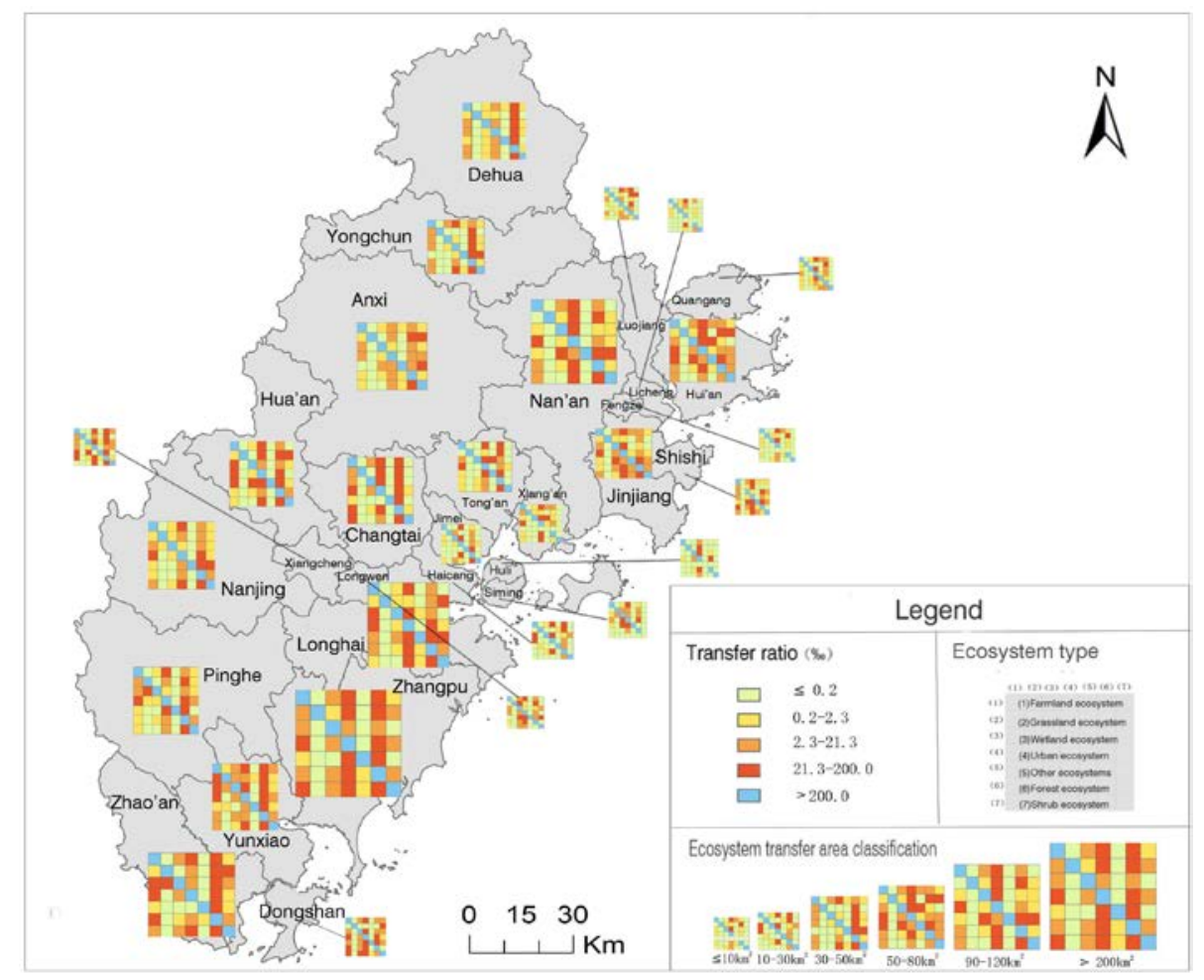

Figure 5. Transfer ratio and scale of ecosystems in the cities and counties of the Min Delta (2010-2015)

(1) Most of the wetland ecosystem transformed into urban and forest regions. Over $21.3 \%$ of the original farmland ecosystem was transformed into urban areas, excluding those in Dehua, Anxi and Huli, and over 21.3\% was transformed into forests in the northwest such as in Dehua, Luojiang in the northeast, Tong'an, Changtai, Xiangcheng, and Haicang in the center of 
the region, and Zhangpu, Yunxiao and Xhao'an in the south. Farmland also clearly became wetland in the eastern region.

(2) Most of the grassland ecosystem was converted into forests and shrubland, and there was a clear trend towards urban ecosystems, especially in regions such as Zhangpu, Changtai, Hua'an, Shishi and Huli.

(3) The pattern of transfer from urban ecosystems to farmland ecosystem increased and became the main type of transfer. For the northwestern cities such as Dehua, Yongchun and Anxi, northeastern cities such as Luojiang, Quangang, Xiangcheng, Fengze and Shishi, and the central cities such as Huli, Siming, Jimei and Licheng, the proportion of farmland exceeded $21.3 \%$.

(4) Forest ecosystems often became farmland and urban areas. A large proportion of forests in Zhao'an, Dongshan, Changtai and Shishi was converted to farmland, and shrub ecosystems were generally converted into forested and urban areas.

\subsection{Analysis of the comprehensive dynamic index}

The comprehensive ecosystem dynamics of the counties and cities in the Min Delta were calculated for each time period, and the results are as

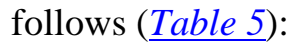

Table 5. Comprehensive dynamic index of the Min Triangle

\begin{tabular}{llllllll}
\hline & \multicolumn{3}{l}{ Comprehensive eco- } & & \multicolumn{3}{c}{ Comprehensive eco- } \\
Name & \multicolumn{3}{l}{ system dynamics (\%) } & Name & \multicolumn{3}{c}{ system dynamics (\%) } \\
Anxi & $00-05$ & $05-10$ & $10-15$ & & $00-05$ & $05-10$ & $10-15$ \\
Dehua & 0.043 & 0.192 & 0.209 & Nan’an & 0.062 & 0.313 & 0.480 \\
Dongshan & 0.002 & 0.149 & 0.206 & Nanjing & 0.022 & 0.134 & 0.362 \\
Fengze & 0.001 & 0.412 & 1.190 & Pinghe & 0.027 & 0.092 & 0.295 \\
Haicang & 0.005 & 0.058 & 0.252 & Quangang & 0.005 & 0.080 & 0.302 \\
Huli & 0.025 & 0.936 & 0.996 & Shishi & 0.009 & 0.157 & 0.547 \\
Hua’an & 0.001 & 0.904 & 0.519 & Siming & 0.001 & 0.467 & 0.583 \\
Hui'an & 0.073 & 0.132 & 0.417 & Tong’an & 0.013 & 0.494 & 0.581 \\
Jimei & 0.002 & 0.198 & 0.974 & Xiangcheng & 0.009 & 0.411 & 0.884 \\
Jinjiang & 0.370 & 0.688 & 0.778 & Xiang'an & 0.035 & 0.734 & 0.724 \\
Licheng & 0.156 & 0.297 & 0.549 & Yongchun & 0.043 & 0.136 & 0.301 \\
Longhai & 0.001 & 0.383 & 0.307 & Yunxiao & 0.037 & 0.309 & 0.765 \\
Longwen & 0.001 & 0.917 & 0.819 & Zhangpu & 0.020 & 0.318 & 1.016 \\
Luojiang & 0.001 & 0.1917 & 0.741 & Changtai & 0.055 & 0.298 & 0.790 \\
\hline
\end{tabular}

As shown in Table 5, the dynamics of ecosystems in counties and cities over the three periods have a clear increasing trend from the level of the previous period. Areas with large changes in ecosystem types are concentrated in the eastern and central parts of the Min Triangle.

From 2000 to 2005, the dynamic degree of ecosystem types in all counties and cities was small, generally below $0.2 \%$, and Jimei was the only region with a dynamic degree greater than $0.2 \%$, which was $0.37 \%$. From 2005 to 2010, the dynamics of regions such as Xiang'an, Huli and Jimei, which are close to the central and eastern parts of Xiamen, as well as Haicang and Longhai, which are located in Zhangzhou City, improved significantly. The dynamics of several counties exceed $0.5 \%$, and the ecosystem dynamics of Haicang, Huli and Longhai exceed $0.9 \%$, at $0.936 \%$, $0.904 \%$, and $0.917 \%$, respectively. The ecosystem dynamics of most counties and cities in the western Min Triangle, such as Huali, Anxi, Hua'an, 
Yongchun and Pinghe, as well as Luojiang, Quangang, Fengze and Hui'an in the northeast, remained below $0.2 \%$ during 2005-2010. The annual rate of change of the ecosystem is low. From 2010 to 2015, the dynamics' degree of Zhangpu, Zhao'an and Yunxiao in the southeast of the study area, as well as Xiangcheng, Longwen and Changtai in the central region, changed significantly from that of the previous period. The dynamics of ecosystems in the central and eastern counties are still relatively large, but not significantly different from the previous period. The change was not obvious, and the dynamics' degree in Huli, Longhai and Xiang'an also decreased slightly. In summary, the annual change rate of ecosystems in the Min Triangle in 2010-2015 was relatively large.

\subsection{Driving forces in the Min Delta urban agglomeration}

Changes in ecosystems are the result of the combined effects of the natural environment, socioeconomic factors, cultural conditions and local policies (Gu et al., 2012). Some results indicate that the influence of human activities on ecosystems will exceed that of natural environmental factors with continuing socioeconomic development and urbanization (Han, Yang, \& Song, 2015). Moreover, human factors are more sensitive to changes in an ecosystem's structure within a shorter period. The above factors should be considered with regard to the principles of comprehensiveness, representativeness, sensitivity and accessibility when selecting factors.

Table 6. Correlation analysis results of ecosystem dynamic attitude and driving factor variables

\begin{tabular}{llllllllll}
\hline \multirow{2}{*}{ Farmland } & Year & $\mathrm{X}_{1}$ & $\mathrm{X}_{2}$ & $\mathrm{X}_{3}$ & $\mathrm{X}_{4}$ & $\mathrm{X}_{5}$ & $\mathrm{X}_{6}$ & $\mathrm{X}_{7}$ & $\mathrm{X}_{8}$ \\
ecosystem & -0.525 & $-0.711^{*}$ & $-0.611^{*}$ & $-0.529^{*}$ & $0.479^{* *}$ & 0.191 & -0.400 & - \\
& $05-10$ & $-0.883^{*}$ & $-0.729^{*}$ & $-0.710^{*}$ & -0.767 & -0.049 & $-0.476^{*}$ & $-0.636^{* *}$ & 0.247 \\
Forest & $10-15$ & $-0.850^{*}$ & $-0.722^{*}$ & $-0.751^{*}$ & -0.737 & 0.053 & -0.154 & $-0.716^{* *}$ & -0.414 \\
ecosystem & $00-05$ & 0.187 & $0.639^{*}$ & 0.146 & 0.362 & $-0.454^{*}$ & -0.149 & -0.150 & - \\
& $05-10$ & 0.350 & $0.768^{*}$ & 0.209 & 0.085 & -0.088 & -0.278 & $-0.389^{*}$ & 0.079 \\
Wetland & $10-15$ & 0.322 & $0.789^{*}$ & -0.038 & 0.037 & -0.039 & 0.240 & 0.115 & -0.114 \\
ecosystem & $00-05$ & $-0.555^{* *}$ & 0.354 & 0.006 & 0.186 & -0.270 & 0.035 & $-0.375^{*}$ & - \\
& $05-10$ & -0.240 & 0.127 & -0.164 & 0.296 & -0.01 & $0.559^{* *}$ & $-0.390^{*}$ & 0.214 \\
Urban & $10-15$ & -0.138 & 0.120 & -0.105 & $0.636^{* *}$ & -0.126 & $0.711^{* *}$ & 0.029 & -0.072 \\
ecosystem & $00-05$ & $0.461^{*}$ & 0.340 & $0.624^{*}$ & $0.701^{* *}$ & 0.202 & -0.028 & $0.831^{*}$ & - \\
& $05-10$ & $0.636^{*}$ & $0.661^{* *}$ & $0.548^{*}$ & $0.745^{* *}$ & 0.135 & 0.061 & $0.865^{*}$ & -0.115 \\
Grassland & $10-15$ & $0.763^{*}$ & $0.692^{* *}$ & $0.679^{*}$ & $0.823^{* *}$ & -0.279 & $-0.455^{*}$ & $0.815^{*}$ & 0.282 \\
ecosystem & $00-05$ & 0.078 & $-0.526^{* *}$ & 0.102 & -0.091 & -0.087 & -0.085 & -0.013 & - \\
& $05-10$ & 0.077 & -0.085 & -0.025 & -0.232 & -0.211 & -0.190 & -0.196 & 0.084 \\
Shrub & $10-15$ & 0.155 & 0.069 & 0.064 & 0.013 & 0.140 & 0.259 & 0.064 & 0.220 \\
ecosystem & $00-05$ & 0.070 & 0.159 & -0.173 & 0.071 & 0.068 & 0.052 & 0.010 & - \\
& $05-10$ & 0.048 & 0.021 & -0.055 & 0.069 & -0.130 & 0.288 & $0.390^{*}$ & 0.009 \\
& $10-15$ & -0.022 & 0.001 & -0.301 & -0.110 & -0.034 & 0.087 & -0.139 & -0.062 \\
\hline
\end{tabular}

** indicates significant correlation at the 0.01 level, * indicates significant correlation at the 0.05 level.

In this study, twelve socioeconomic and anthropogenic indicators, including the agricultural output value, forestry, animal husbandry and fishery production values, GDP, secondary industry, tertiary industry, percapita GDP, permanent population, and urbanization rate, were selected. Colinear tests were performed to exclude non-representative indicators. The change value of these indicators in five-year statistical units was then calculated. Eight final indicators were selected, including the agricultural $\left(\mathrm{X}_{1}\right)$, forestry $\left(\mathrm{X}_{2}\right)$ and fishery production values $\left(\mathrm{X}_{3}\right)$, GDP $\left(\mathrm{X}_{4}\right)$, 
secondary industry $\left(\mathrm{X}_{5}\right)$, tertiary industry $\left(\mathrm{X}_{6}\right)$, permanent population $\left(\mathrm{X}_{7}\right)$, and urbanization rate $\left(\mathrm{X}_{8}\right)$. All the above data were the changed values and were compared with the dynamics of each ecosystem in each county and city for each five-year period. The main factors driving the urban agglomeration of the Min Delta were discussed in combination with the results of the statistical and Pearson-related analyses.

\subsubsection{Analysis of driving factors of farmland ecosystem}

The correlation coefficient table indicates (Table 6) that the changes in the agricultural, forestry and fishery production values, GDP, tertiary industry, and the resident population are negatively correlated with the dynamics of farmland ecosystems. This indicates that, with increasing economic development, the output value of agriculture, forestry and fishing will be higher, the urban population will be larger, the urbanization level will be higher, and the proportion of farmland ecosystems will reduce. The correlation coefficient is significant, indicating that the agricultural, forestry, fishery and gross production values, tertiary industry change value, resident population and urbanization rate all have a strong driving effect on farmland ecosystem changes. The above correlation coefficient first increased and then decreased during the three periods of 2000-2005, 20052010 and 2010-2015, indicating that these driving forces on the farmland ecosystem first increased and then decreased.

Combined with relevant statistics, it can be seen that, with the intention of establishing an "urban town and an ecological city", counties in Zhangzhou will intensively develop the agricultural economy and create a "hometown of fruits" and a "capital of flowers." This has promoted the transformation of the agricultural ecosystem in each county of Zhangzhou.

From 2000 to 2005, Haicang optimized its agricultural structure, developed high-quality ecological agriculture, and increased the agricultural output value of the whole region by 2.35 billion. Tong'an strengthened exchanges with Taiwanese farmers and constructed a fruit seedling center and Yangtao base. Further, Xiang'an has increased the construction of agricultural infrastructure.

From 2005 to 2010, the "One Village, One Product" agricultural development goal of Tong'an and new rural areas was established in Xiang'an. Three rural areas were developed in Xiamen, and urban agriculture and agricultural pioneering parks were upgraded in 2010-2015. The establishment of these will aid in the acceleration of the transformation of the farmland ecosystem.

\subsubsection{Analysis of driving factors of urban ecosystems}

The correlation coefficient table (Table 6) indicates that, for farmland ecosystems, the changes in the agricultural, forestry and fishery production value, GDP and the resident population are positively correlated with the dynamics of urban ecosystems. This indicates that, with a more developed economy, the output values of agriculture, forestry. and fishing will be higher, the urban population will be larger, and the proportion of urban ecosystems will increase. The correlation coefficient is significant, indicating that the agricultural, forestry and fishery production values, GDP, and the resident population have strong driving effects on changes in urban ecosystems. The above correlation coefficient increased during the three 
five-year study periods, indicating that these driving forces on the urban ecosystem were continuously decreasing.

Combining this with the relevant statistics, it can be seen that the real estate industry in Siming District developed rapidly from 2000 to 2005, and a large number of residential buildings and communities were constructed. Industrial Parks developed rapidly in Siming, Huli, and Haicang, and public facilities continued to improve. The transportation industries in Xiang'an, Jinjiang and Hui'an continued to grow, and the coverage of transportation facilities increased.

From 2005 to 2010, the construction of commercial districts in Siming and Huli began, along with new towns in the Jimei and Xiang'an Districts, and the process of urbanization was accelerated. Some industrial enterprises moved to Tong'an. The creation of special industries in Jinjiang, Shishi, Hui'an, Nan'an and Quanzhou, stimulated economic development and expanded the area of industrial land. The secondary and tertiary industries of Xiangcheng, Longwen and Longhai developed rapidly, and transportation facilities were continuously strengthened.

From 2010 to 2015, the infrastructure in Min Delta improved, and the industrial economies of Zhangzhou and Quanzhou steadily grew. The establishment of the free trade zone in Xiamen attracted more new industries. In addition, many regions in Xiamen promoted the "two violations" treatment and the demolition and reconstruction of unsuitable buildings. These are the main reasons for the transfer of urban ecosystems in these areas.

\subsubsection{Analysis of driving factors for forest and wetland ecosystem}

The correlation coefficient table (Table 6) indicates that, for forest ecosystems, the changes in the agricultural and forestry production values, GDP and the resident population were positively correlated with the dynamics of forest ecosystems. This indicates that economic development, increase in the agricultural and forestry production values, and the increase in the urban population will accelerate the conversion of forest ecosystems. The changes in the output value of secondary and tertiary industries were negatively correlated with the dynamics of the forest ecosystem, indicating that the development of industry and service industry will limit the changes in the area of forest ecosystems. The changes in the forestry output value are significantly related to the dynamic nature of forest ecosystems, indicating that the forestry output value has a strong driving effect on the changes in forest ecosystems.

From 2005 to 2010, the changes in the agricultural production value and the change in resident population were negatively correlated with the dynamics of wetland ecosystems, indicating that these are the main driving forces of wetland ecosystem change in 2000-2005, and an increase in the agricultural production value and permanent population size will limit the transformation of wetland ecosystems. From 2005 to 2010, the dynamics of wetland ecosystems were positively correlated with the changes in the tertiary industry, and negatively correlated with the changes in the permanent population. Therefore, these are the main driving forces of the changes in the wetland ecosystem from 2005 to 2010; the development of tertiary industry will accelerate the transformation of the wetland ecosystem, and the changes in the permanent population will limit the changes in wetland ecosystems. From 2010 to 2015, the dynamics of the wetland ecosystem were significantly positively correlated with the changes in GDP 
and tertiary industry, indicating that these were the main driving forces of the changes in wetland ecosystems from 2005 to 2010, and the development of GDP and tertiary industry would accelerate the transformation of the wetland ecosystem.

There was no notable correlation between grassland and shrub ecosystems and the above indicators, therefore, they will not be discussed further.

\section{CONCLUSION}

From 2000 to 2015, the area of farmland, forest and shrub ecosystems in the Min Triangle decreased, and the areas of urban, wetland and grassland ecosystems increased. The areas with the largest decline in forest ecosystems were concentrated in Pinghe, Zhangpu, Nan'an and Anxi. The areas with the largest decline in farmland ecosystems were concentrated in Zhangpu and Nan'an. The areas with the largest increase in urban ecosystems were concentrated in Zhangpu, Nan'an, Longhai, Hui'an and Nanjing. The areas with the largest increase in wetland ecosystems were concentrated in Hui'an, Dongshan and Longhai.

According to the ecosystem transfer matrix of the Min Triangle, from 2000 to 2015, the areas with a large proportion of farmland ecosystem to urban ecosystem were concentrated in the northeastern region. In areas in the southwest and southeast, farmland ecosystems were converted to urban ecosystems, and this is more notable in the east than the west. Urban and farmland ecosystems were transformed in two directions. Grassland ecosystems were converted to farmland and forest in the west, while small areas of wetland and urban ecosystems were converted. In the northeast areas, large areas of grassland ecosystems were transformed into urban areas, and a small area was converted to forest. Wetland ecosystems were commonly converted to urban areas in the east and the farmland and forests in the west. The shift in ecosystem types between different time periods was in line with the general trend, but there were slight differences between regions. The trends in the eastern region were centered on Xiamen and extend to the east, and east of Quanzhou. The trends in the western region gradually weakened over time.

According to the comprehensive dynamic index, from 2000 to 2015, the degree of ecosystem dynamics was higher in each period than the previous, and the dynamics in the eastern and central parts during the same period were higher than those in the west and south. From 2000 to 2005, the comprehensive dynamic index was generally below $0.2 \%$. The dynamics index of Longhai in Xiamen and Zhangzhou during 2005-2010 increased significantly from that of the previous period, and their values all exceeded $0.9 \%$. From 2010 to 2015, the area with a large change in the dynamics index expanded to the east and south, and included the central area of Xiamen. The dynamics in the northwest did not significantly increase.

The agricultural, forestry and fishery production values, GDP and tertiary industry change value, permanent population and the urbanization rate all have a strong negative driving effect on the changes in farmland ecosystems. Meanwhile, the agricultural, forestry and fishery production values, GDP and the permanent population have a strong positive driving effect on the change of urban ecosystems. Forestry production has a strong positive driving effect on the change of forest ecosystems, while industrial production and the urban population have a negative driving effect. The 
output value of tertiary industry has a positive driving effect on the wetland ecosystem, and the permanent population has a negative driving effect.

\section{ACKNOWLEDGMENT}

This research is supported by the National Key research and development program of China (No. 2016YFC0502901)

\section{REFERENCES}

Chen, W. J., Ma, G. X., Cai, L. L., Luan, X. F., \& Li, G. C. (2013). "Research on the Spatial Pattern Characteristics of the Urban Connections in the Pearl River Delta-Based on Analysis of Intercity Passenger Traffic Flow", Economic Geography, 33(4), 48-55.

Du, Q., Xu, H. L., Zhang, P., Zhang, P., Ling, H. B., \& Zhao, G. P. (2015). "Analysis on the Changes of Ecological Environment Characteristics in the Tarim River Basin from 1990 to 2010 Based on Rs/Gis Methods", Chinese Journal of Soil Science, 46(4), 803-809.

Environmental Protection Department of China, \& Chinese Academy of Science (2017). Remote Sensing Survey and Assessment Project of Ten Year Changes in Ecological Environment (2000-2010), Science Press, Beijing.

Fan, J., \& Jiang, Z. L. (2015). "Computer Network Information Center of Chinese Academy of Sciences (面向计划的区域可持续发展系统解决方案研究)", Progress in Geography, 34(1), 1-9. https://doi.org/10.11820/dlkxjz.2015.01.001

Geospatial Data Cloud (2010). "Computer Network Information Center of Chinese Academy of Sciences",. Retrieved from http://www.gscloud.cn/

Gu, J. L., Zhang, H. T., Chen, J. Y., Ren, Y., \& Guo, L. (2012). "Analysis of Land Use Spatial Autocorrelationpatterns Based on Dem Data (基于 DEM 的县域土地利用空间自 相关格局分析)", Transactions of the Chinese Society of Agricultural Engineering, 28(23), 216-224.

Han, H. R., Yang, C. F., \& Song, J. P. (2015). "The spatial-temporal characteristic of land use change in Beijing and its driving mechanism", Economic Geography, 35(5), 148-154.

Hu, S. S., Chen, Z. W., \& Chen, W. H. (2018). "The Study on Land Cover Change Remote Sensing Monitoring and Landscape Pattern Change in Fujian Delta Region", Journal of Fujian Normal University (Natural Science Edition), 34(3), 27-37.

Hu, Y. F., Yan, Y., Yu, G., Liu, Y., \& Alateng, T. (2012). "The ecosystem distribution and dynamics in Xilingol League in 1975-2009.", Scientia Geographica Sinica, 32(9), 1125 1130.

Li, H., Zhao, S., \& Wang, D. (2015). "Urbanization Patterns of China 's Cities in 19902010", 3(4), 5-17. https://doi.org/http://dx.doi.org/10.14246/irspsd.3.4_5

Li, Z. Y., \& Chen, W. H. (2018). "Analysis on Ecosystem Service Value of Land Use Change in Min Delta", Journal of Fujian Normal University (Natural Science Edition), 33(1), 7884.

Liao, Z. H., Sun, J. R., Fan, S. J., Wu, D., Ren, M. Z., \& Zhou, J. (2015). "Characteristics and Influencing Factors of Air Pollution Change in the Pearl River Delta Region from 2006 to 2012", China Environmental Science, 35(2), 329-336.

Lin, J. H., Chen, W. H., Qi, X. H., Cheng, R. T., \& Chen, Z. W. (2018). "Evolution Pattern of Ecosystem and Its Driving Mechanism in Jian Delta Region", Chinese Journal of Ecology, 37(1), 203-210.

Liu, G. L., Zhang, L. C., \& Zhang, Q. (2014). "Spatial and temporal dynamics of land use and its influence on ecosystem service value in Yangtze River Delta", Acta Ecologica Sinica, 34(12), 3311-3319.

Lu, L., \& Tang, Y. Y. (2014). "Spatial Behavior Patterns of Domestic Tourists of the Zhujiang River Delta Metropolitan Area", Scientia Geographica Sinica, 34(1), 10-18.

Lu, Y. H., \& Nie, M. H. (2008). "Xiamen's Comparative Advantage in the Development of Tourism Industry in Min Delta", Economic Research Guide, (10), 168-170.

Meng, D. Y., Li, X. J., \& Lu, Y. Q. (2014). "Evolvement of spatial pattern of urban economic development in Yangtze River Delta", Economic Geography, 34(2), 50-57.

Mou, X. J., Zhao, X. Y., \& Rao, S. (2016). "Changes of ecosystem structure in Qinghai-Tibet Plateau Ecological Barrier Area during recent ten years", Acta Scientiarum Naturalium Universitatis Pekinensis, 52(2), 279-286. 
Qiao, W. F., Sheng, Y. H., Fang, B., \& Yahua, W., Y. H. (2013). "Land use change information mining in highly urbanized area based on transfer matrix: A case study of Suzhou, Jiangsu Province", Geographical Research (地理研究), 32(8), 1497-1507.

Shi, L. Y., Cui, S. H., \& Yin, K. (2010). "The Impact of Land Use/Cover Change on Ecosystem Service in Xiamen", Acta Geographica Sinica, 65(6), 708-714.

Song, H. (2016). "Spatial and Temporal Characteristics of Land Use/Cover and Ecological Degradation in Shanxi Province from 2000 to 2010", Northwest University.

Wang, W., Cao, Z. L., Peng, K. G., \& Liao, B. (2014). "Study on Dynamic Changes of Ecosystem Patterns and Spatial Structure in Jiangxi Province Based on Rs and Gis", JiangXi Science, 32(5), 617-623.

Xu, X. L., Liu, J. Y., Shao, Q. Q., \& Fan, J. W. (2008). "The dynamic changes of ecosystem spatial pattern and structure in the Three-River Headwaters region in Qinghai Province during recent 30 years", Geographical Research (地理研究), 27(4), 829-839.

Yan, L. H. (2007). "A Comparative Study of the Economic Development of the Min Triangle and the Pearl River Delta and the Yangtze River Delta_-Based on Economic Statistics from 1985 to 2005", Fujian Forum (Social Science Education Edition), (12), 120-125.

Yu, G. M. (2011). "Ecological System Spatio-Temporal Changes and Driving Mechanism of Xi- Linguole City", Shandong Normal University.

Yu, H. R., \& Pu, C. L. (2012). "Study on the Research Situation of Land Use/Cover Change", Economic Research Guide, (19), 142-144.

Zhang, G. H., Zhang, P. C., \& Zhang, X. F. (2017). "Research Progress of Land Use/Cover Change and Driving Force in Three Gorges Reservoir Area", Soil and Water Conservation in China, (5), 47-51.

Zhou, L., \& Jiang, J. L. (2015). "Comprehensive Evaluation of Urban Tourism Competitiveness in the Yangtze River Delta and Its Spatial Patterns Analysis", Economic Geography, 35(1), 173-179.

Zhu, J. L., \& Li, Z. L. (2015). "Coupling coordination development of industry-populationspace in city cluster of Yangtze river-delta region", China Population, Resources and Environment, 25(2), 75-82. 